\title{
Las estatuas de verracos y las fíbulas zoomorfas celtibéricas
}

\author{
ANTONIO BLANCO FREIJEIRO *
}

Ambas manifestaciones del arte antiguo de la Meseta coinciden en buena parte de sus respectivas áreas de difusión. Las estatuas alcanzan más lejos por el sur, rebasando con mucho la Cordillera Central por las provincias de Toledo y Cáceres, mientras que se quedan más cortas por el norte, sin llegar a las provincias de Soria, Burgos y Palencia, donde en cambio las fibulas menudean. Es probable también que ambas manifestaciones sean diacrónicas, con una mayor antigüedad para las fíbulas.

Sólo unas palabras sobre las fíbulas de caballo y de jinete, por haber sido las que primero y más han llamado la atención. Hubo en la antigüedad un foco de producción en el norte de Italia, y otro en la Meseta, con tantos extremos coincidentes, que desde los tiempos del viejo Déchelette nadie se ha atrevido a negar su parentesco, pese a faltar intermediarios y testigos de la ruta por la que la relación pudo ser entablada. En los dos grupos se manifiesta la tendencia a acortar o suprimir las piernas del jinete y a decorar el cuerpo del caballo con circulitos concéntricos (fig. 1). $A$ esto, que ya Déchelette observó ${ }^{1}$, añade Schüle con acierto, que los juegos de anillas que muchos caballitos (fig. 1,1 y 6), toros (fig. 2,11), cerdos y otros animales estilizados que estas fibulas muestran, como caso excepcional en la península, se encuentran también en las fíbulas italianas a partir del siglo vilı a.C. ${ }^{2}$. La relación le parece tan clara a este

* Real Academia de la Historia, Madrid.

'J. DeCHELETTE, Manuel d'archeologie prehistorique. celtique et gallo-romaine, III, $2 .{ }^{\circ}$ ed., Paris, 1927, pags. 343 ss.

W. Schulle: Die Meseta-Kulturen der lberischen Halbinsel, Berlin, 1969, pág. 71. 

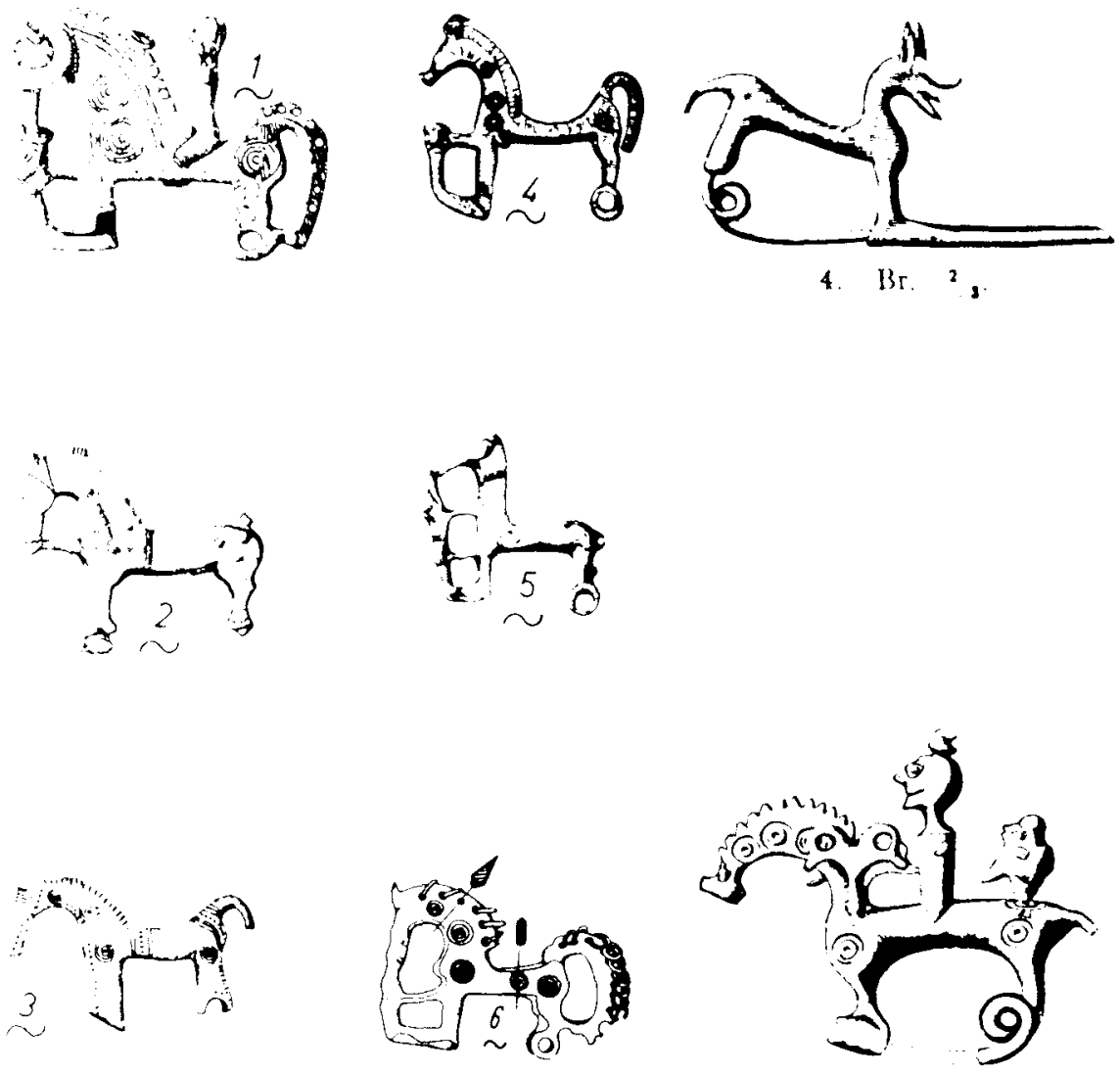

Fig. 1. Fibulas de caballito, españolas, del Duero (n. ${ }^{\text {s }}$ 1-6), e italianas, de Este (arriba, derecha) y Bolonia (derecha, abajo).

autor, poco dado como él es a admitir relaciones de este tipo, que considera a las fibulas zoomorfas de la por él llamada Cultura del Duero como de indudable origen norteitaliano y estealpino (zweifelos norditalischer-ostalpiner Herkunft).

Hay que señalar, sin embargo, una diferencia notable: que mientras que las fibulas italianas son de una pieza, y de resorte muy simple, las hispanas se componen de una que comprende al animal, con la mortaja al pie y el ojal en la cabeza de fíbula; de un eje, y del alfiler, con su doble resorte; en suma, la construcción denominada "ballesta". 


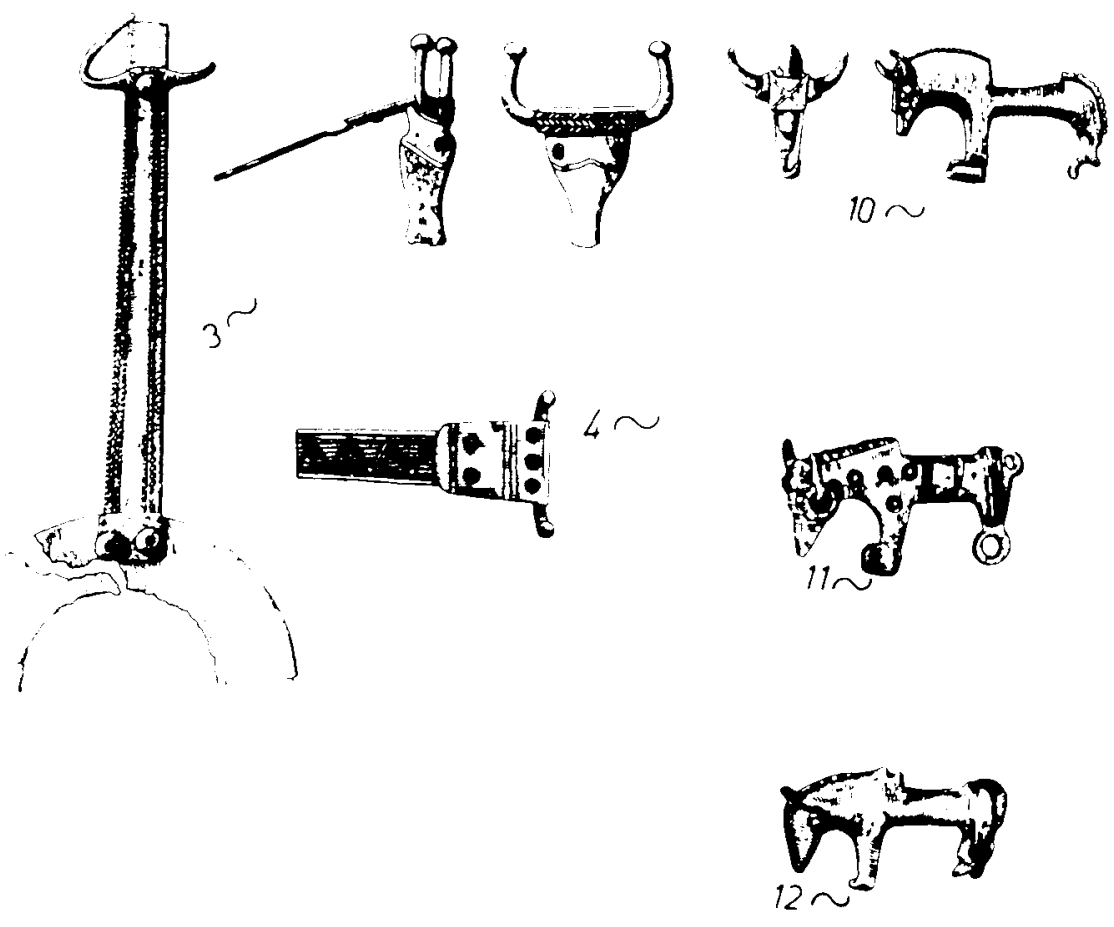

Fig. 2. Mango de un cazo de reborde ancho ( $n .^{\circ}$ 3) y extremo del asa de otro, rematado en cabeza de toro, de cuernos embolados (n." 4), de Lara de los Infantes, y tres fibulas tauriformes ( $n .^{\circ} 10,11$ y 12) de la zona del Duero, las dos últimas con la cola echada sobre la grupa.

Las fibulas de toritos escasean tanto, que apenas se registran seis de ellas, pero difieren entre si lo bastante para admitir que tal vez fueran en su dia más abundantes de lo que parece. Su rareza pudiera ser debida a que no era costumbre depositarlas en tumbas. Schüle las considera muy naturalistas (sehr naturalistisch ausgebildet). supongo que por comparación con los cerdos y cabalitos; a mi me parecen bastante estilizados. Tienen en común, la cabeza situada a nivel más bajo que la cruz, adornada a veces con argollas debajo de los cuernos, o con un aspa incisa en la frente; el vientre, muy prieto, y en los tres ejemplares que la representan, la cola arrollada sobre la grupa con la borla cayendo sobre una de las ancas (fig. 2,11 y 12). Tanto la posición de la cabeza 
como la de la cola coinciden con las habituales en los toros de piedra. Sobre este último pormenor deciamos en nuestro estudio de los verracos: "El interés en dejar bien claro el sexo masculino de toros y cochinos obliga a los artistas no sólo a poner muy en evidencia los órganos genitales de unos y otros, sino a echar hacia un lado las colas. El cerdo suele tenerla ladeada como cosa natural, pero no así el toro; de modo que para conseguir quitarla de en medio y que no oculte u oscurezca los testículos, la enroscan en todos los casos sobre la grupa, de modo que la borla caiga sobre una de las ancas. En ciertos ejemplares, como sucede en dos de los Toros de Guisando, la erosión ha llegado a borrar por completo los rabos, pero el número de ejemplos conservados es más que suficiente para acreditar que ningún toro rompe con la norma establecida" ${ }^{3}$.

Los cerdos abundan en las fíbulas más que los toros y ofrecen una gama más variada. Es posible incluso que fueran jabalies, pues tienen la jeta alargada que los cazadores expertos, y casi todos lo son, llaman con propiedad "trompa", bajo la que asoman las amoladeras y las navajas, como dicen a sus afilados y corvos colmillos ${ }^{4}$. En la Antigüedad el cerdo doméstico y el jabali no se habian distanciado tanto como lo están hoy en el mundo civilizado tras la ingerencia del cerdo chino en occidente. Sea como fuere, los toreutas antiguos del Duero hacian mucho uso del cochino para adorno de las conteras (fig. 5,2 ) de las guardas o "ricassi» de sus hermosos puñales (fig. 5,1); pero sobre todo, para los puentes de sus fíbulas, acentuando mucho la longitud de la trompa del animal y encorvándola hacia arriba, tanto como para que en casos se preste a confusión con un proboscideo (fig. 3, 20,21, 26). Por lo demás, el animal es enjuto y bien proporcionado, hecho seguramente a partir de estatuillas, como una diminuta del instituto de Valencia de Don Juan (fig. 3,19), en el que la estilización y los adornos se armonizan con el naturalismo del modelo vivo. Ya en las fibulas, los dos pares de patas se funden, de dos en dos, en sendos pivotes; el delantero lleva incorporada la mortaja, mientras que el trasero lleva el ojal del eje del resorte. Hay ejemplares compuestos de un doble prótomo (fig. 3,26), jabalies janiformes como el del relieve de Pozo Moro ${ }^{5}$. También se produce el fenómeno contrario:

1984.

4 CONDE DE YEBES: Veinte años de caza mayor, Madrid, 1943.

5 M. Almagro Gorbea: "Los relieves mitológicos orientalizantes de Pozo Moro", Trab. de Prehist. XXXV, 1978, págs. 262, 266, 277, lám. VII. 

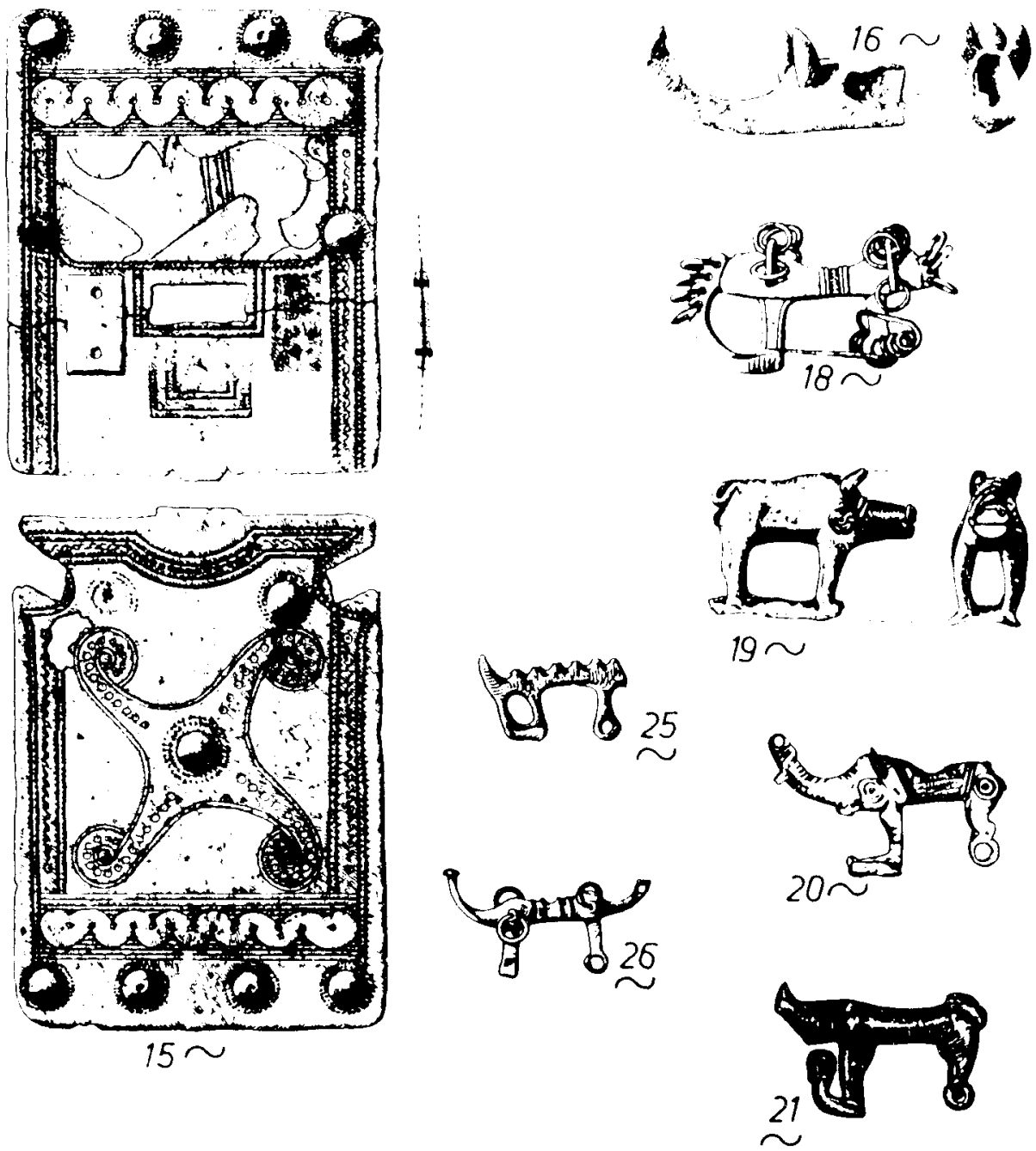

Fig. 3. Broche de cinturón ( . $\left.^{\circ} 15\right)$, contera de espada (n. ${ }^{\circ}$ 16) y fibula de doble grupa, con anillas, ( $n .^{\circ}$ 18) de la Tumba 60 de Miraveche. Estatuilla de verraco ( $n .{ }^{\circ}$ 19) y fibulas de cerdito ( $n^{\circ} 20$ y 21) de la zona del Duero, y dos ejemplares, el primero de ellos $\left(n .^{\circ} 25\right)$ falto de un extremo, de doble prótomo porcino ( $n .^{\circ}$ 26). 
el compuesto de sólo dos grupas, irreconocible, si no supiésemos de dónde viene (fig. 3,18).

En muchos casos ei cuerpo del jabali se desentiende de la forma natural y se convierte en un medio cilindro por arriba y en un plano tajante por abajo. En un ejemplar muy interesante, el cerdo (fig. 3,20) ostenta unos tatuajes de circulos concéntricos y de rayitas que recuerdan a las "retrancas» de algunos verracos de piedra, las que Gómez-Moreno llamaba "verdugones" ${ }^{6}$ (fig. 4). Tanto o más interesante que este es otro ejemplar que exhibe en su parte delantera una tête coupée puesta encima de un pilarcillo, como algunas fibulas de caballito (fig. 3,21).

La mezcla de elementos naturales estilizados con otros de puro arte abstracto alcanza una increible perfección en un hallazgo de la Baja An-
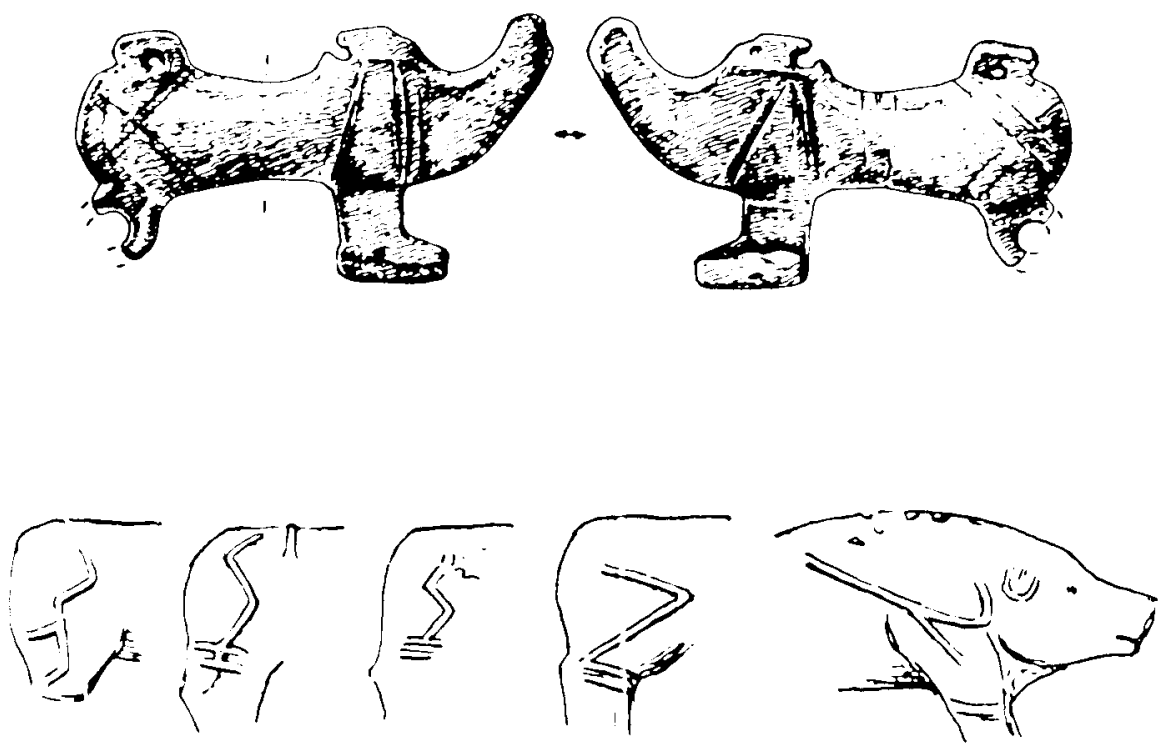

Fig. 4. Arriba: Verdugones en una fíbula de Paredes de Nava (Palencia), según J. A. Moure y L. Ortega. Abajo: señales análogas en esculturas de toros y verracos de Avila y Segovia, según Gómez-Moreno.

'M. Gomez-Moreno. Misceláneas, Madrid, 1949, pág. 136. 
dalucía, del que el profesor Eduardo Ripoll, y quien esto escribe en su homenaje, poseemos sendas reproducciones en plata ${ }^{7}$. La pieza mide 0,038 de longitud máxima. El grado de abstracción es tan extremado, que a las personas poco acostumbradas a ver este tipo de arte les cuesta reconocer al cochino, y si no se les advierte, no lo conseguirán (fig. 6). Los elementos naturales del animal son la cabeza, con sus orejas y hocico adornados de aros, y la grupa, con dos adornos laterales del mismo tipo y unos testículos prominentes, muy parecidos a los del verraco denominado "Marranita de Villalazán" hoy en el Museo de Zamora ${ }^{8}$. El semicilindro del cuerpo está surcado por cuatro estrías verticales, que no tendria sentido llamar costillas, porque se parecen más al alambre del resorte que a ningún elemento de un cuerpo vivo; también el reborde del hocico y la parte inferior de la mortaja están estriados de esa forma.

¿De dónde habrá salido esta admirable y minúscula obra de arte? Sus paralelos nos llevarían al norte del Duero, desde Palencia a Burgos. En la primera hay un antiguo "oppidum", el de Paredes de Nava, que ha proprocionado ejemplares del mismo tipo y de otros muy afines ${ }^{9}$. Pero es en la Miraveche burgalesa donde parece radicar el foco principal de este arte más abstracto que naturalista. Una de sus fibulas de doble grupa (fig. 3,18 ), aun perteneciendo a otro tipo, se diria obra de la misma mano. En las guardas de las espadas levantan sus hocicos prótomos de cochinos muy similares (fig. 3,16 y 5,1B) y abstracciones de los mismos (fig. 3 y $5,1 \mathrm{~A}$ ). En las conteras de las mismas espadas montan guardia parejas heráldicas de estos verraquillos (fig. 5,2 A y B), y una placa de cinturón nos da la sorpresa de ofrecer un grabado del animal (fig. 3,15), que parece un dibujo de J. Mariscal, y no dudamos de que éste lo suscribiria. Las orejas puntiagudas y la faja estriada que ciñe su cuerpo revelan su parentesco con nuestra fíbula, pero hay algo más, muy bien visto por Schüle en esta placa de Miraveche: el estilo de los animales del Koban, presente en una de las hebillas de un túmulo de Sainz Remèze (Ardèche), se hace presente aquí indicando una ruta que desde el norte de Italia y los Alpes piamonteses llega hasta la Meseta ${ }^{10}$. El broche

${ }^{7}$ El original es de bronce como sus congéneres, y propiedad del Prof. Rafael GarciaDiéguez, que ha tenido la gentileza de reproducirlo y suplir en plata las piezas que faltan en el original (resorte y algunos anillos).

${ }^{8}$ Blanco Freijeiro, en nota 3, fig. 38. Otro ejemplo similar en el verraco de la Plazuela de S. Martín de Segovia, ibid. fig. 34.

9 J. A. Moure, L. Ortega: "Fibulas con esquemas de La Tène procedentes de Paredes de Nava (Palencia)", Numantia, 1981, 133 ss.

${ }^{10}$ W. SChUlE: op. cit., en nota 2, págs. 153 ss. 


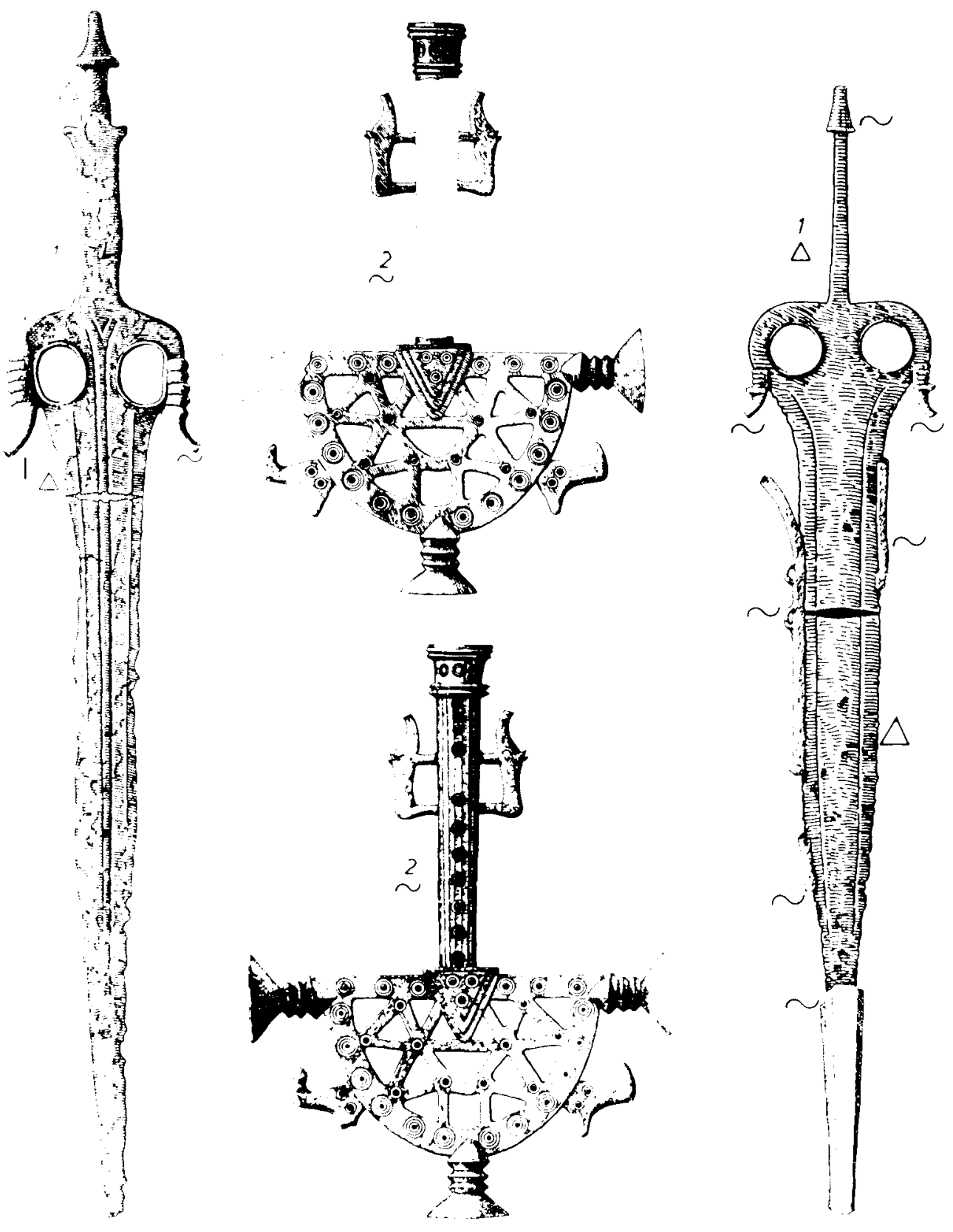

Fig. 5. Espadas cortas y conteras de vainas de espadas de Miraveche. Museo Arqueológico Provincial de Burgos. Esc. 1/2. Según W. Schüle. 

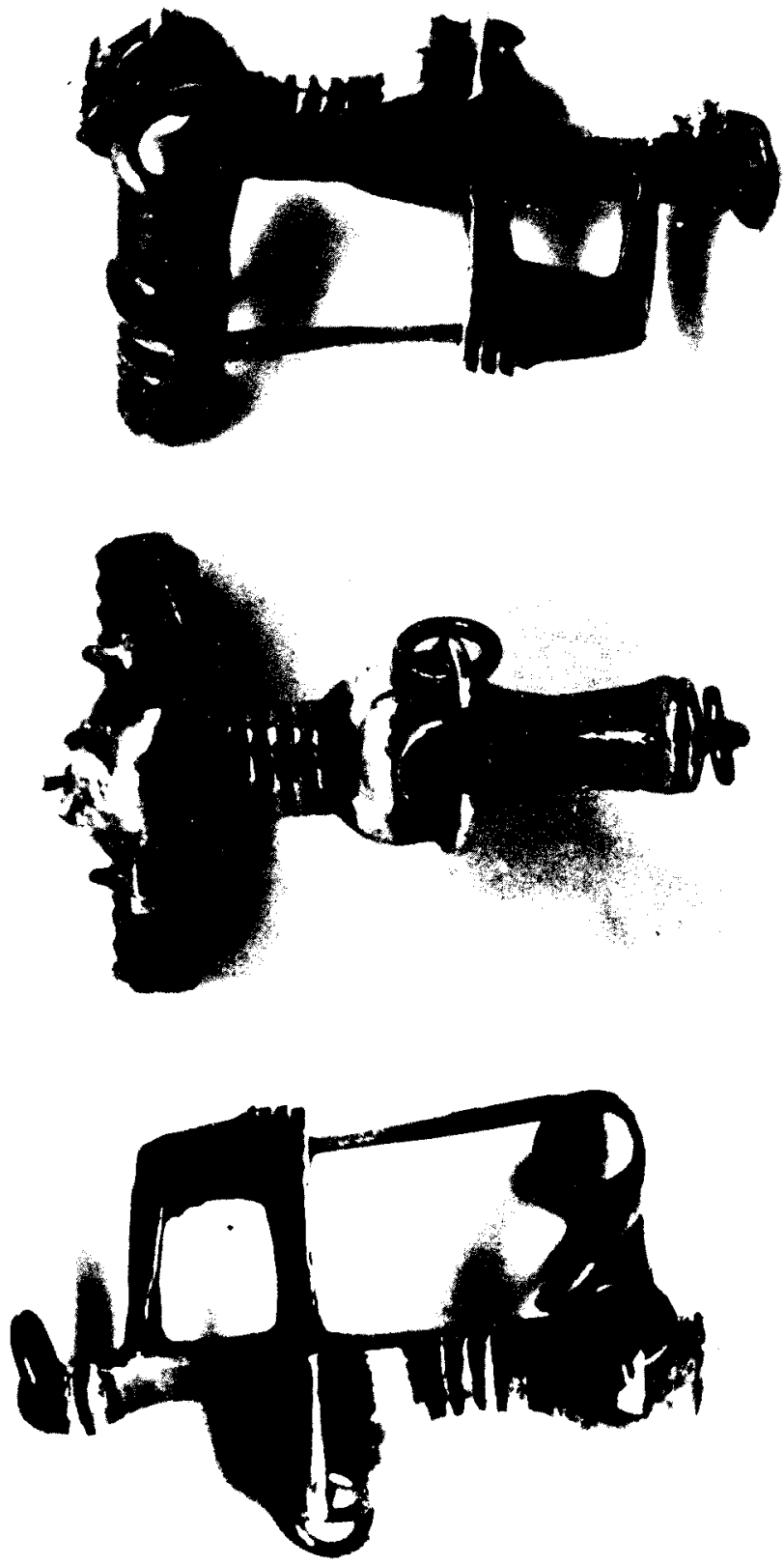

Fig. 6. Reconstrucción de una fibula de cerdito celtiberica realizada por su propietario el prof. J. L. Garcia-Diéguez (Colecciones E. Ripoll y A. Blanco). 
languedociense, de principios del siglo $\mathrm{VI}$, debiera prevenir al que quiera dar fechas muy bajas a estas manifestaciones artísticas. En todo caso hay que tener presente que el rico expolio de Miraveche es anterior al año 400 a.C., y que probablemente la "piara" de cerditos de bronce del yacimiento comenzó a existir en el siglo vI.

Sundwall ha sido uno de los últimos en señalar el origen de las fibulas de caballito, especialmente las de los Alpes orientales en formas existentes en el Caúcaso. Aun sin ir tan lejos, su antigüedad y su ascendencia norteitaliana resultan bastante claras, y la consecuencia a sacar sería que la animalística del Duero - caballos, toros, cerdos, pájaros, "tortugas"- no proviene del Oriente ni del mundo clásico arcaico, sino del hallstáttico.

Emparentados con los toritos de las fibulas y coetáneos de ellos están una serie de cabezas y de pares de cuernos que decoraban los extremos de unos cazos rituales que parecen haber sido especialmente frecuentes en el castro de Lara de los Infantes, de donde provienen los bronces de la Colección Monteverde examinados también por Schüle. Una de las cabezas (fig. 2,4) y algunos de los cuernos parecen pertenecer a toros embolados. Si estos los fuesen, constituirian un importante indicio de la práctica de los juegos de toros, en cacerías rituales como las de las taurokathapsiai tesalias, de origenes muy remotos aunque las descripciones llegadas a nosotros sean tardias. En otras palabras, en estas cabecitas se podría ver el primer hito histórico de la tauromaquia hispánica y el antecedente de los toros embolados portugueses. 